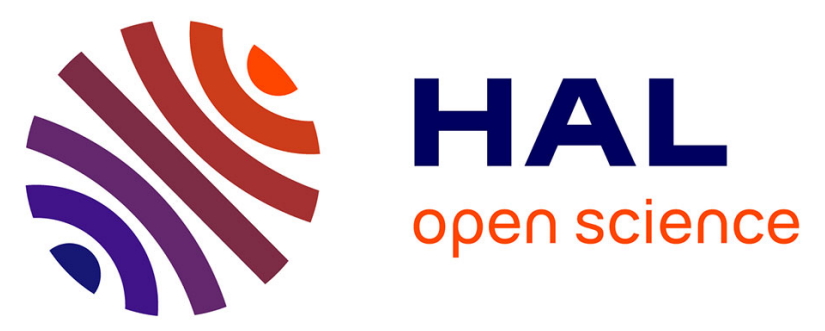

\title{
Surgical site infection after valvular or coronary artery bypass surgery: 2008-2011 French SSI national ISO-RAISIN surveillance
}

S. Cossin, S. Malavaud, P. Jarno, M. Giard, F. L 'Hériteau, Loïc Simon, L Bieler, L. Molinier, B. Marcheix, Anne-Gaelle Venier, et al.

\section{To cite this version:}

S. Cossin, S. Malavaud, P. Jarno, M. Giard, F. L 'Hériteau, et al.. Surgical site infection after valvular or coronary artery bypass surgery: 2008-2011 French SSI national ISO-RAISIN surveillance. Journal of Hospital Infection, 2015, 91 (3), pp.225-230. 10.1016/j.jhin.2015.07.001 hal-01237658

HAL Id: hal-01237658

https://hal-univ-rennes1.archives-ouvertes.fr/hal-01237658

Submitted on 9 Dec 2015

HAL is a multi-disciplinary open access archive for the deposit and dissemination of scientific research documents, whether they are published or not. The documents may come from teaching and research institutions in France or abroad, or from public or private research centers.
L'archive ouverte pluridisciplinaire HAL, est destinée au dépôt et à la diffusion de documents scientifiques de niveau recherche, publiés ou non, émanant des établissements d'enseignement et de recherche français ou étrangers, des laboratoires publics ou privés. 
A.-G. Venier et al.

Surgical site infection after valvular or coronary artery bypass surgery: 2008-2011 French national SSI-RAISIN surveillance

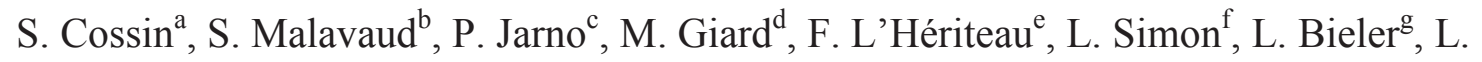
Molinier $^{\mathrm{g}}$, B. Marcheix ${ }^{\mathrm{h}}$, A.-G. Venier ${ }^{\mathrm{a},{ }^{*}}$ and the ISO-RAISIN Steering Committee $\dagger$

${ }^{\mathrm{a}}$ CHU, CCLIN Sud-Ouest, Bordeaux, France

${ }^{\mathrm{b}} \mathrm{CHU}$, Service d'hygiène hospitalière, Toulouse, France

${ }^{\mathrm{c}} H U$, CCLIN Ouest, Rennes, France

${ }^{\mathrm{d}}$ CHU, CCLIN Sud-Est, Lyon, France

${ }^{\mathrm{e}}$ CHU, CCLIN Paris-Nord, Paris, France

${ }^{\mathrm{f}} \mathrm{CHU}$, CCLIN Est, Nancy, France

${ }^{\mathrm{g}} \mathrm{CHU}$, Département d'information médicale, Toulouse, France

${ }^{\mathrm{h}} \mathrm{CHU}$, Chirurgie cardio-vasculaire, Toulouse, France

*Corresponding author. Address: CHU, CCLIN Sud-Ouest, F-33000 Bordeaux, France. Tel.: +33556796058.

E-mail address: anne-gaelle.venier@chu-bordeaux.fr(A.-G. Venier).

$\dagger$ ISO-RAISIN Steering Committee: L. Simon, O. Ali-Brandmeyer, C. Neels, P. Jarno, M. Aupée, M. Perennec, P. Astagneau, F. L'Hériteau, F. Daniel, C. Campion, M. Giard, C. Bernet, E. Caillat-Vallet, A.-G. Venier, C. Bervas, E. Reyreaud, P. Baillet, Yannick, J.L. Jost, V. Merle, L. Merlo, J. Christophe, S. Malavaud, F. Bruyere, J.-M. Thiolet, S. BarquinGuichard.

SUMMARY

Background: Multisite information regarding surgical site infection (SSI) rates for cardiac surgery programmes is not widely available. Ward characteristics that may affect outcomes have not been analysed previously.

Aim: To determine individual- and ward-level factors associated with SSI occurrence after coronary artery bypass grafting (CABG) and valvular surgery.

Methods: A dataset from the French national database SSI-RAISIN 2008-2011 was used. Only adult patients were included. A standardized questionnaire was completed for each patient who underwent surgery, and patients with and without SSI were characterized. Patients and ward risk factors for SSI were analysed using a multilevel logistic regression model with SSI as binary outcome (two levels: patient and ward).

Results: Out of 8569 patients from 39 wards, the SSI rate was 2.2\%. Micro-organisms were isolated in 144 patients (74\%): 35\% coagulase-negative staphylococci $(N=51), 23 \%$ 
Staphylococcus aureus $(N=33), 6 \%$ Escherichia coli $(N=8)$. Higher probability of SSI was associated with the duration of preoperative hospitalization, the duration of follow-up, the duration of surgery $>75$ th percentile and the SSI rate in the surgery ward. The residual heterogeneity between wards (median odds ratio: 1.53) was as relevant as duration of preoperative hospitalization (odds ratio: 1.57).

Conclusion: Although patient risk factors were more strongly associated with SSI occurrence, this study provided evidence for the existence of a ward-level effect. This should be taken into account when considering possible corrective interventions.

Keywords:

Cardiac surgery

Coronary artery bypass graft

Surgical site infection

Surveillance

Valvular surgery

\section{Introduction}

Surveillance systems (along with infection control programs) can reduce surgical site infections (SSI) rates. ${ }^{1-3}$ SSI after cardiac surgery increase the patient morbidity and mortality, the length of hospital stay and hospital costs. ${ }^{4}$ Multisite information regarding SSI rates for cardiac surgery programmes is not readily available. Moreover, SSI risk factors after coronary artery bypass graft (CABG) and valvular surgery have rarely been assessed by population-based or multicentre studies. Previously identified risk factors, such as obesity, are generally not amenable to corrective action. ${ }^{4-7}$ By identifying the role of the specific risk factors related to the treating facility, such as ward characteristics, it is possible that interventions could be undertaken to reduce SSI rates. ${ }^{8}$ The aim of this study was to describe SSI after CABG and valvular surgery from the French national database SSI-RAISIN 2008-2011, in order to identify significant individual- and ward-level factors associated with SSI occurrence.

\section{Methods}

\section{Population}

A dataset of adult patients who underwent a valvular or CABG surgical procedure during the four-year period 2008-2011 was analyaed: 8569 patients from 39 wards from 31 healthcare facilities.

\section{Data collection}

Yearly surveillance included at least three months during the annual survey period (January to June). Details of data collection and management methods for the SSI-RAISIN 
system have been previously published. ${ }^{1,9}$ SSI diagnostic criteria used by surgical teams accorded with the standardized Centers for Disease Control definitions. This study was given ethical clearance by the French data protection authority.

A sternal wound infection included at least one of the following: (i) presence of purulent drainage; (ii) bacterial isolation from the incision; (iii) presence of at least one of the following symptoms: tenderness, swelling, redness, or heat; (iv) diagnosis made by the surgeon or physician.

A standardized data collection form was completed for each patient who underwent surgery during the surveillance periods. For cardiac surgery, the classification of the procedure was categorized as follows: closed-heart surgery, open-heart surgery, CABG with saphenous vein graft, CABG with internal thoracic arterial graft, valvular surgery, and intrathoracic arteries surgery as categorized by the French Medical Acts Classification.

The following preoperative characteristics were considered: age, sex, duration of preoperative hospitalization ( $<48 \mathrm{~h} \mathrm{vs} \geq 48 \mathrm{~h}$ ), wound class (Altemeier classification), the American Society of Anesthesiologists (ASA) physical status score, duration of surgery ( $\leq 75$ th percentiles versus $>75$ th percentiles; the 75 th percentile was $5 \mathrm{~h}$ for CABG with the use of internal thoracic arteries, $4 \mathrm{~h}$ with the use of saphenous vein and for valvular procedures), emergency versus elective surgery, ambulatory surgery, type of procedure, duration of postoperative follow-up, SSI occurrence during hospitalization or after discharge, depth of infection (superficial, deep, organ/space), average delay between the surgery and SSI diagnosis, revisions surgery, patient outcome (alive/deceased), National Nosocomial Infections Surveillance system (NNIS) risk index of the surgery (based on risk factors for infection: ASA classification $>2$, duration of surgery $>75$ th percentile, and wound contamination $>2){ }^{10}$

The following ward-based characteristics were considered: hospitalization ward, global cardiac surgery SSI rate, valvular and CABG SSI rate, the number of cardiac surgery procedures per month, the average duration of patients' follow-up after surgery, and the proportion of NNIS 0 patients.

Statistical analysis

First, a descriptive analysis of patients with and without SSI was performed with the $\mathrm{R}^{\circledR}$ software version 2.15.3.

Risk factors for SSI were estimated with a multilevel logistic regression model with SSI as a binary outcome. ${ }^{11}$ Data structure had two levels: patients (first level) and wards (second level). An 'empty' model (model A) only included a random intercept and allowed detection of a possible contextual dimension. Thereafter, the individual characteristics were 
included in the model (model B) to investigate the extent to which ward incidence differences were explained by the individual patients of the wards. Ward characteristics were included in a third model (model C). Multivariate analyses were performed by stepwise logistic regression. All variables with $P \leq 0.10$ in the univariate analysis or which were thought to be associated with SSI from the literature were included in the models. $P<0.05$ was considered significant. ${ }^{12-15}$ For quantifying heterogeneity between clusters, the median odds ratio (MOR) was calculated and intraclass correlation (ICC) was estimated with the linear threshold model method. ${ }^{16}$ MLwiN $^{\circledR}$ software 2.15 was used for univariate and multivariate analyses.

\section{Cost assessment}

The cost assessment adopted the healthcare payer's perspective, the healthcare insurance, and took into account only hospitalization costs. Hospitalization costs (such as nursing, medical care, pharmacy, diagnostic tests, staff, general equipment, administration, security, central supply, dietetics or social services) were assessed using the French diagnosisrelated groups that fund all costs. ${ }^{17,18}$ The average additional cost of valvular or coronary artery bypass surgery with a deep SSI compared to the same support without SSI was estimated from the database of the University Hospital of Toulouse $(€ 11,000)$. The total additional cost was calculated by multiplying the total number of deep SSIs by the estimated average incremental cost. Costs were expressed in euros.

\section{Results}

The SSI rate was $2.5 \%$ in 2008 (52/2071), $1.9 \%$ in 2009 (35/1815), 2.2\% in 2010 $(45 / 2075)$, and $2.3 \%$ in $2011(62 / 2698)$ with no significant difference between years $(P=$ $0.60)$.

\section{Ward characteristics}

Only five wards participated in the surveillance every year. The number of valvular and $\mathrm{CABG}$ surgeries per month ranged from 11 to 111 [median: 44; interquartile range (IQR): 26-77]. The proportion of NNIS-0 patients on the various wards ranged from 0 to $80 \%$ (median: 2.5\%; IQR: 1-6\%).

Six healthcare facilities had two different surgery wards performing cardiac surgery and one had three different wards: as there were substantial differences in SSIs between wards in the same healthcare facility, these wards were considered separately.

Ward SSI rates ranged from 0\% to 5\% (median: 1.7\%; IQR: 0.7-2.9; cf. Figure 1). At ward level, the mean duration of patient's follow-up was 32 days (mean: 30; IQR: 9-41). Patient characteristics

Out of $8659 \mathrm{CABG}$ or valvular procedures, the overall SSI rate was $2.2 \%$. Patient characteristics are recorded in Table I: $61 \%$ of SSIs were diagnosed during hospitalization, 
$45 \%$ were superficial SSIs and $48 \%$ deep or organ space (sternitis, mediastinitis, and endocarditis) SSI. Depth of infection was not specified for 12 patients $(6 \%)$.

Average $( \pm \mathrm{SD})$ time from surgery to SSI onset was 14 days $( \pm 7.14)$ without significant difference being noted between CABG and valvular surgery. The mean duration of hospital stay after surgery was 23 days in SSI patients versus 10 days in those without SSI $(P<0.01)$. Mortality was 4.6\% in SSI patients (9/194) versus 2.4\% (205/8465) in patients without infection $(P=0.06)$; further surgery was required in $45.2 \%$ of the SSI patients (only two patients without SSI underwent an additional surgery).

Comparing the patients with deep-organ space sternal SSI versus the patients with superficial SSI, there were no differences with respect to the interval to diagnosis, causative micro-organisms or NNIS score. However, patients with deep SSI tended to have a longer length of hospital stay (32 days versus 19 days, $P<0.001$ ), a longer duration of follow-up (45 days versus 30 days, $P<0.001)$, a higher mortality ( $9.6 \%$ versus $0 \%$ ), and a higher risk of revision surgery $(67.8 \%$ versus $20 \%, P<0.001)$.

\section{Microbiology}

Micro-organisms were isolated in 144 (74\%) patients: 35\% coagulase negativestaphylococci $(N=51), 23 \%$ Staphylococcus aureus $(N=33)$ including five meticillinresistant $S$. aureus (MRSA), 6\% Escherichia coli $(N=8), 5 \%$ Pseudomonas aeruginosa $(N=$ 7), $3 \%$ Enterococcus faecalis $(N=4), 3 \%$ other Gram-positive bacteria $(N=4), 2 \%$

Citrobacter koseri $(N=3), 2 \%$ Serratia spp. $(N=2)$, and $8 \%$ other Gram-negative bacteria $(N$ $=11)$. Five patients had two micro-organisms identified, 15 had three (10\%). Cultures were negative in eight patients, not performed in five patients and information was missing in 37.

S. aureus was found in six out of nine patients (67\%) who developed SSI and died before discharge, including two patients with MRSA. No trends between years were observed.

Results of multivariate analysis are presented in Table II. Model A was an empty model with no explanatory variable. The part of the residual variance attributed to ward level was $7 \%$ and was significantly different from zero (i.e. $7 \%$ of total variability of the outcome variable was explained by differences between wards). In a model with patients' characteristics only (model B), a higher probability of SSI was associated with the duration of preoperative hospitalization, the duration of follow-up, the duration of surgery $>75$ th percentile. ASA score, wound contamination class, sex, and age were not significantly associated with SSI. Model B included the separated components of NNIS score and was preferred to a model including NNIS [NNIS score: OR: 1.67 (95\% CI 1.23-2.270); MOR: 
1.52; ICC: 0.06]. The residual heterogeneity between wards (MOR: 1.53) was equal to the duration of preoperative hospitalization (OR: 1.57).

In univariate analysis, only the ward SSI rate was significantly associated with higher probability of SSI. In a multivariate model with both patient and ward characteristics (model C), a higher probability of SSI was associated with the duration of surgery $>75$ th percentile and the ward SSI rate.

Cost

The total additional cost of SSI for facilities was estimated to be $€ 291,000$ for 94 patients during the four years studied. If hospital financing did not reimburse a part of the costs of the SSI, the costs would have increased to $€ 1,034,000$ for the facilities.

\section{Discussion}

This analysis using a national dataset found a 2.2\% incidence rate of SSI after valvular and CABG surgery within the first 30 days following surgery. This result is consistent with previous nationwide studies. ${ }^{5,6}$ A significant heterogeneity of SSI occurrence between wards was found. This is, to our knowledge, the first nationwide study showing the contribution of ward risk factors in cardiac surgery SSI.

Several limitations to the present study should be noted. Whereas the protocol recommended a minimum follow-up of 30 days, methods differed between the wards. ${ }^{3}$ Despite this issue, we believe that underdiagnosis of infection was unlikely since no patient developed an SSI after 22 days. ${ }^{19,20}$ The study was restricted to the wards that carried out more than 10 cardiac procedures in order to prevent the great variability of small samples which could generate bias in the multilevel analysis. An additional issue which could have affected analysis was the fact that only one type of procedure could be defined on the surveillance form. Surgeons had to choose between CABG or valvular procedure, even when patients underwent a combined procedure. Nevertheless, our findings were in line with literature showing a higher rate of SSI after CABG than after valvular repair. ${ }^{6,14,21}$

This study also confirmed the impact of several previously identified individual risk factors. The impact of the preoperative length of stay was confirmed as noted in previous reports. This phenomenon is probably multifactorial, including increased colonization with hospital pathogens or progressive impairment of the patient's nutritional status and is unlikely to be impacted by interventions. ${ }^{23}$ Since this factor disappeared in the model along with ward characteristics, further investigation of the phenomenon should be carried out.

Duration of surgery may reflect either the patient's preoperative morbidity, operating room logistics, or difficulties during the surgery. ${ }^{21}$ Cristofolini et al. pointed out that the ASA risk group may not be applicable in cardiac surgery since almost all patients exhibit an ASA 
score $\geq 3$, which was the case in our study. ${ }^{24}$ The wound contamination class seems irrelevant in the types of cardiac surgery we studied; the NNIS score index should therefore not be used to compare SSI rates after cardiothoracic operations among surgeons or institutions. ${ }^{25}$ The logistic EuroSCORE I and II or the Society of Thoracic Surgeons risk score (STS score) should be more appropriate than NNIS for cardiac surgery but was not available at the time of the study. ${ }^{26}$

Coagulase-negative staphylococci and S. aureus were implicated in half of the cases of SSIs. These organisms have various virulence factors and are usually found on the skin and the environment which can explain their predominance in SSI after cardiac surgery. ${ }^{27,28}$ The importance of these pathogens has led to recommendations for the use of nasal mupirocin for all cardiac surgery cases. ${ }^{29}$

We used a multilevel modelling technique to take into account the hierarchical data structure and the correlation of within-group observations. This study showed a significant correlation of infections and the ward location of the patient after adjusting for patient-level variables. In an empty model, we found a between-patient and between-ward heterogeneity. MOR indicated that the ward of hospitalization would be relevant for understanding variations of the individual probability of acquiring SSI. Healthcare-associated infection prevention practices may explain variation in rates between healthcare facilities. A higher incidence of SSI in the ward was associated with higher probability of SSI for a patient: this relationship could be a reflection of the ward ecology, colonization pressure or suboptimal compliance with infection control measures, none of which was could be evaluated in this survey. Furthermore, organization and patient safety culture differences may also have a role. ${ }^{30}$ Although the use of intraoperative antibiotic bone paste and the use of antibioticimpregnated sutures were associated with a lower risk of developing SSIs, the differences were not significant. ${ }^{22}$ SSI surveillance is considered to be an effective strategy for reducing SSI incidence, as well as a tool for surgical staff to promote awareness and prevention, but French SSI surveillance was unable to identify specific reasons for ward-related infection risks. Indeed, the findings of our study suggest that more precise and detailed ward characteristics should be included in future cardiac surgery SSI studies in the hope of identifying interventions which could further decrease the risk of these infections.

The present study provided clear evidence of the impact of ward-level variables on the occurrence of SSI in CABG and valvular surgery. Although patient risk factors were more strongly associated with the SSI occurrence, the impact of ward characteristics was not negligible. Ward risk factors should be evaluated by the surgery team and infection control teams by performing root cause analysis to improve patients' quality of care. ${ }^{31,32}$ 


\section{Acknowledgements}

We thank the infection control and surgical teams at the healthcare facilities who participated in the RAISIN-ISO surveillance.

\section{Conflict of interest statement}

None declared.

\section{Funding sources}

The French national surgical site infection surveillance system is supported by the French Ministry of Health.

\section{References}

1. Astagneau P, L'Hériteau F, Daniel F, et al. Reducing surgical site infection incidence through a network: results from the French ISO-RAISIN surveillance system. $J$ Hosp Infect 2009;72:127-134.

2. Desenclos J-C. RAISIN - a national programme for early warning, investigation and surveillance of healthcare-associated infection in France. Euro Surveill 2009;14:46.

3. Perennec-Olivier M, Jarno P. Surveillance des infections du site operatoire, France 2011 [Surveillance of surgical site infections, France 2011]. Saint-Maurice: Institut de veille sanitaire; 2012.

4. Alasmari FA, Tleyjeh IM, Riaz M, et al. Temporal trends in the incidence of surgical site infections in patients undergoing coronary artery bypass graft surgery: a populationbased cohort study, 1993 to 2008. Mayo Clin Proc 2012;87:1054-1061.

5. Berg TC, Kjørstad KE, Akselsen PE, et al. National surveillance of surgical site infections after coronary artery bypass grafting in Norway: incidence and risk factors. Eur J Cardiothorac Surg 2011;40:1291-1297.

6. Manniën J, Wille JC, Kloek JJ, van Benthem BHB. Surveillance and epidemiology of surgical site infections after cardiothoracic surgery in The Netherlands, 2002-2007. J Thorac Cardiovasc Surg 2011;141:899-904.

7. Steingrimsson S, Gottfredsson M, Kristinsson KG, Gudbjartsson T. Deep sternal wound infections following open heart surgery in Iceland: a population-based study. Scand Cardiovasc J 2008;42:208-213.

8. Beckmann A, Doebler K, Schaefer E, Koetting J, Gastmeier P, Graf K. Sternal surgical site infection prevention - is there any room for improvement? Eur J Cardiothorac Surg 2011;40:347-351.

9. Rioux C, Grandbastien B, Astagneau P. Impact of a six-year control programme on surgical site infections in France: results of the INCISO surveillance. J Hosp Infect 2007;66:217e223. 
10. Altemeier WA, Burke JF, Pruit BA, Sandusky WR. Definitions and classifications of surgical infections. Manual on control of infections in surgical patients. Philadelphia: Lippincott; 1984. 19-30.

11. Goldstein H. Multilevel statistical models, 4th ed. Chichester, UK: John Wiley \& Sons; 2011.

12. Crabtree TD, Codd JE, Fraser VJ, Bailey MS, Olsen MA, Damiano Jr, RJ. Multivariate analysis of risk factors for deep and superficial sternal infection after coronary artery bypass grafting at a tertiary care medical center. Semin Thorac Cardiovasc Surg 2004;16:53-61.

13. Berríos-Torres SI, Mu Y, Edwards JR, Horan TC, Fridkin SK. Improved risk adjustment in public reporting: coronary artery bypass graft surgical site infections. Infect Control Hosp Epidemiol 2012;33:463-469.

14. Eklund AM, Lyytikäinen O, Klemets P, et al. Mediastinitis after more than 10,000 cardiac surgical procedures. Ann Thorac Surg 2006;82:1784-1789.

15. Farsky PS, Graner H, Duccini P, et al. Risk factors for sternal wound infections and application of the STS score in coronary artery bypass graft surgery. Rev Bras Cir Cardiovasc 2011;26:624-629.

16. Merlo J, Chaix B, Ohlsson $\mathrm{H}$, et al. A brief conceptual tutorial of multilevel analysis in social epidemiology: using measures of clustering in multilevel logistic regression to investigate contextual phenomena. J Epidemiol Community Health 2006;60:290-297.

17. Ye X, Lafuma A, Torreton E, Arnaud A. Incidence and costs of bleeding-related complications in French hospitals following surgery for various diagnoses. BMC Health Serv Res 2013;13;186.

18. Yilmaz E, Raynaud D. The influence of social deprivation on length of hospitalisation. Eur J Health Econ 2013;14:243-252.

19. Wilson J, Ramboer I, Suetens C. Hospitals in Europe Link for Infection Control through Surveillance (HELICS). Inter-country comparison of rates of surgical site infection opportunities and limitations. J Hosp Infect 2007;65:165-170.

20. Manniën J, Wille JC, Snoeren RLMM, van den Hof S. Impact of postdischarge surveillance on surgical site infection rates for several surgical procedures: results from the nosocomial surveillance network in The Netherlands. Infect Control Hosp Epidemiol 2006;27:809-816.

21. Parisian Mediastinitis Study Group. Risk factors for deep sternal wound infection after sternotomy: a prospective, multicenter study. J Thorac Cardiovasc Surg 1996;111:1200-1207. 
22. Haley VB, Van Antwerpen C, Tsivitis M, et al. Risk factors for coronary artery bypass graft chest surgical site infections in New York State, 2008. Am J Infect Control 2012;40:22-28.

23. Leung Wai Sang S, Chaturvedi R, Alam A, Samoukovic G, de Varennes B, Lachapelle K. Preoperative hospital length of stay as a modifiable risk factor for mediastinitis after cardiac surgery. J Cardiothorac Surg 2013;8:45.

24. Cristofolini M, Worlitzsch D, Wienke A, Silber R-E, Borneff-Lipp M. Surgical site infections after coronary artery bypass graft surgery: incidence, perioperative hospital stay, readmissions, and revision surgeries. Infection 2012;40:397-404.

25. Roy MC, Herwaldt LA, Embrey R, Kuhns K, Wenzel RP, Perl TM. Does the Centers for Disease Control's NNIS system risk index stratify patients undergoing cardiothoracic operations by their risk of surgical-site infection? Infect Control Hosp Epidemiol 2000;21:186-190.

26. Paul M, Raz A, Leibovici L, Madar H, Holinger R, Rubinovitch B. Sternal wound infection after coronary artery bypass graft surgery: validation of existing risk scores. $J$ Thorac Cardiovasc Surg 2007;133:397-403.

27. Söderquist B. Surgical site infections in cardiac surgery: microbiology. APMIS 2007;115:1008-1011.

28. Elgharably H, Mann E, Awad H, et al. First evidence of sternal wound biofilm following cardiac surgery. PLoS One 2013;8:e70360.

29. Van Rijen M, Bonten M, Wenzel R, Kluytmans J. Mupirocin ointment for preventing Staphylococcus aureus infections in nasal carriers. Cochrane Database Syst Rev 2008;(4):CD006216.

30. Benn J, Burnett S, Parand A, Pinto A, Vincent C. Factors predicting change in hospital safety climate and capability in a multi-site patient safety collaborative: a longitudinal survey study. BMJ Qual Saf 2012;21:559-568.

31. Khorsandi M, Skouras C, Beatson K, Alijani A. Quality review of an adverse incident reporting system and root cause analysis of serious adverse surgical incidents in a teaching hospital of Scotland. Patient Saf Surg 2012;6:21.

32. Venier AG. Root cause analysis to support infection control in healthcare premises. $J$ Hosp Infect 2015;89:331-334. 


\section{Table I}

Univariate analysis of patients with and without surgical site infection (SSI) after coronary artery bypass graft or valvular surgery (SSI-RAISIN 2008-2011)

\begin{tabular}{|c|c|c|c|c|c|}
\hline \multirow[t]{2}{*}{ Variable } & \multicolumn{2}{|l|}{ Infection } & \multirow[t]{2}{*}{$N$} & \multirow{2}{*}{$\begin{array}{l}\text { SSI } \\
\text { rate }\end{array}$} & \multirow[t]{2}{*}{$P$-value } \\
\hline & $\begin{array}{l}\text { SSI } \\
(N=194)\end{array}$ & $\begin{array}{l}\text { Control group } \\
(N=8465)\end{array}$ & & & \\
\hline Mean \pm SD age (years) & $68.2 \pm 11.1$ & $69.6 \pm 11.1$ & 8659 & & 0.07 \\
\hline Mean \pm SD time of patient follow-up (days) & $38.2 \pm 30.8$ & $30.8 \pm 25.5$ & 8659 & & 0.001 \\
\hline Male sex & $132(68 \%)$ & $5816(69 \%)$ & 8435 & & 0.95 \\
\hline Preoperative length of stay ( $>2$ days) & $67(35 \%)$ & $2195(26 \%)$ & 8530 & & 0.01 \\
\hline Emergency surgery & $7(4 \%)$ & $260(3 \%)$ & 8094 & & 0.77 \\
\hline NNIS score & & & 8110 & & 0.001 \\
\hline 0 & $5(2.6 \%)$ & $314(3.7 \%)$ & & 1.6 & \\
\hline 1 & 113 & 5925 & & 1.9 & \\
\hline 2 & 58 & 1675 & & 3.5 & \\
\hline 3 & & 19 & & 5.3 & \\
\hline ASA score & & & 8175 & & 0.09 \\
\hline 1 & 1 & 67 & & 1.5 & \\
\hline 2 & 6 & 384 & & 1.6 & \\
\hline 3 & 133 & 6308 & & 2.1 & \\
\hline 4 & 40 & 1182 & & 3.4 & \\
\hline 5 & 1 & 53 & & 1.9 & \\
\hline Wound contamination class & & & 8402 & & 0.26 \\
\hline 1 & 180 & 8027 & & 2.2 & \\
\hline 2 & 2 & 112 & & 1.8 & \\
\hline 3 & 1 & 46 & & 2.2 & \\
\hline VY & 1 & 33 & & 3.0 & \\
\hline Duration of surgery $>75$ th percentiles & $61(31 \%)$ & $1830(22 \%)$ & 1891 & & 0.01 \\
\hline
\end{tabular}

NNIS, National Nosocomial Infections Surveillance system; ASA, American Society of Anesthesiologists. 


\section{Table II}

Multivariate analysis of risk factors for surgical site infection after coronary artery bypass graft or valvular surgery (SSI-RAISIN 2008-2011)

\begin{tabular}{|c|c|c|c|}
\hline Variable & Model A & Model B & Model C \\
\hline Intercept & $-3.881(0.118)$ & $-4.278(0.433)$ & $-4.524(0.463)$ \\
\hline \multicolumn{4}{|l|}{ Patient characteristics } \\
\hline \multirow[t]{2}{*}{ Age $\geq 65$ years } & & 0.755 & 0.988 \\
\hline & & $(0.550-1.035)$ & $(0.974-1.001)$ \\
\hline \multirow[t]{2}{*}{ Male sex } & & 1.023 & 1.018 \\
\hline & & $(0.729-1.436)$ & $(0.725-1.429)$ \\
\hline Duration of preoperative & & 1.573 & 1.462 \\
\hline hospitalization $\geq 48 \mathrm{~h}$ & & $(1.138-2.173)$ & $(1.062-2.012)$ \\
\hline Duration of postoperative & & 1.007 & 0.898 \\
\hline follow-up & & $(1.001-1.013)$ & $(0.660-1.219)$ \\
\hline \multirow[t]{2}{*}{ ASA score $>2$} & & 1.274 & 1.309 \\
\hline & & $(0.583-2.778)$ & $(0.593-2.869)$ \\
\hline \multirow[t]{2}{*}{ Wound contamination class $>2$} & & 0.880 & 0.738 \\
\hline & & $(0.209-3.775)$ & $(0.174-3.131)$ \\
\hline Duration of surgery $>75$ th & & 1.820 & 1.756 \\
\hline percentile & & $(1.299-2.550)$ & $(1.275-2.416)$ \\
\hline
\end{tabular}

Ward characteristics

Percentage of NNIS-0 patients

1.006

$(0.965-1.048)$

No. of valvular and CABG

1.000

surgeries per month

(0.992-1.007)

Ward SSI rates

1.724

(1.480-2.000)

Median OR (95\% CI)

1.59

1.53

1.05

(1.431-1.791)

(1.451-1.760)

(1.010-1.08)

Intraclass correlation coefficient

0.067

0.058

0.001

NNIS, National Nosocomial Infections Surveillance system; ASA, American Society of Anesthesiologists; CABG, coronary artery bypass graft; OR, odds ratio; CI, confidence interval; NNIS-0 patient: ASA score $\leq 2+$ wound contamination class $\leq 2+$ duration of surgery $\leq 75$ th percentile. 
Figure 1. Distribution of the 2008-2011 surgical site infection (SSI) rate in valvular and coronary artery bypass graft surgery, French national SSI Surveillance ISO RAISIN $(N=39$ wards).

\section{Author queries}

1. Please confirm full postal address for corresponding author.

2. Please check the names 'J. Christophe' and 'Yannick' in the study group list.

3. Please note that original ref. 10 was a duplicate of ref. 1 and has been removed - please check renumbering. 


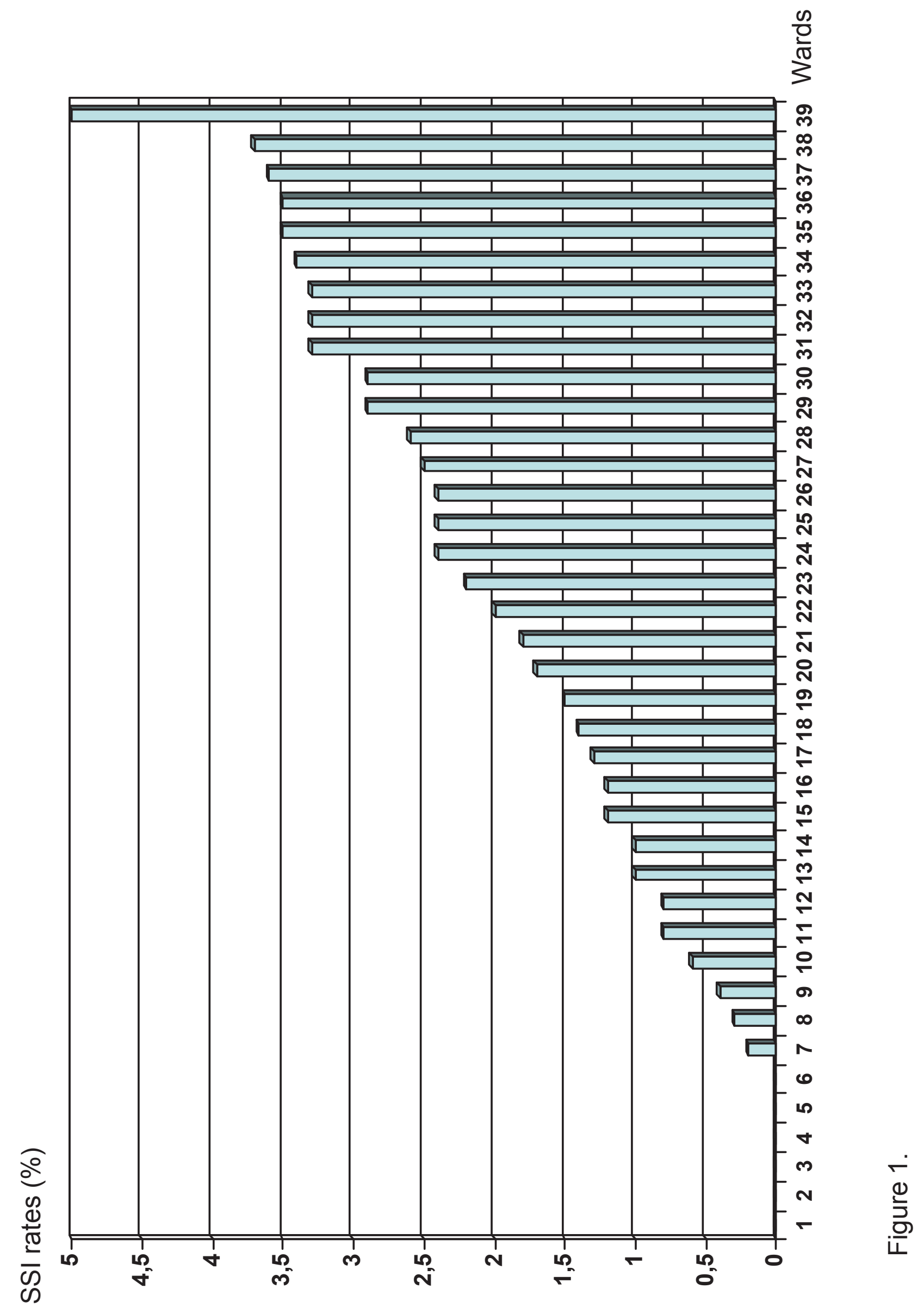

